\title{
Cardiac Fibroma Revealed at Adulthood....!!
}

\author{
Nawal DOGHMI ${ }^{1,3}$, Oumaima ALAIKA ${ }^{1,3 *}$, Youssef EL FAKIR ${ }^{2,3}$ and Mohamed CHERTI ${ }^{1,3}$ \\ ${ }^{1}$ Department of Cardiology B, Ibn Sina Hospital, Mohammed V University, Morocco \\ ${ }^{2}$ Radiology center, Agdal Clinic, Rabat, Morocco \\ ${ }^{3}$ Faculty of Medicine and Pharmacy of Rabat, Mohammed V University, Morocco \\ *Corresponding author: Oumaima ALAIKA, Ibn Sina Hospital, Abderrahim Bouabid Avenue, Rabat, Morocco
}

\begin{tabular}{|c|c|}
\hline ARTICLE INFO & ABSTRACT \\
\hline Received: 仹 December 04, 2021 & $\begin{array}{l}\text { Citation: Nawal DOGHMI, Oumaima ALAIKA, Youssef EL FAKIR, Mohamed CHER- } \\
\text { TI. Cardiac Fibroma Revealed at Adulthood....!!. Biomed J Sci \& Tech Res 40(3)-2021. }\end{array}$ \\
\hline Published: 櫘 December 14, 2021 & BJSTR. MS.ID.006469. \\
\hline
\end{tabular}

\section{Short Communication}

A 37-year-old man without known comorbid conditions or cardiovascular risk factors presented with lipothymia. The neurological and cardiovascular examinations were normal. The brain magnetic resonance imaging was normal. Electrocardiogram (EKG) showed LV hypertrophy with $\mathrm{T}$ waves inversion in inferolateral leads (A). 24-hours EKG Holter showed a sinusal rhythm with no further abnormalities. Transthoracic echocardiography (TTE) revealed a left ventricular hypertrophy localized in the inferior wall suggestive of myocardial mass (B) with normal left ventricle ejection fraction. In the subsequent cardiac magnetic resonance (CMR) imaging, a $7.6 \times 2.6 \mathrm{~cm}$ mass was found. The mass was well demarcated, lined with normal myocardial tissue, hyperintense on $\mathrm{T} 1$ weighted images (C), hypointense on $\mathrm{T} 2$ weighted images (D), and showed extensive late gadolinium hyperenhancement (E; F). Those CMR findings were consistent with cardiac fibroma. Despite of the known risk for arrhythmias of cardiac fibroma, the decision was made to closely follow this patient without excisional surgery given the normal sinus rhythm, the absence of history of syncope or resuscitated sudden death and the patient preference. Cardiac fibroma is the second most common primary pediatric cardiac tumor after rhabdomyoma. It remains a rare entity, especially in the adult population. Clinical presentation of patients with cardiac fibroma depends on the location and size of the tumor. CMR imaging is an excellent tool for evaluation of patients with suspected cardiac masses as it provides excellent tissue characterization and may give information about the possible etiology of cardiac mass thus foregoing the need for myocardial biopsy (Figure 1). 


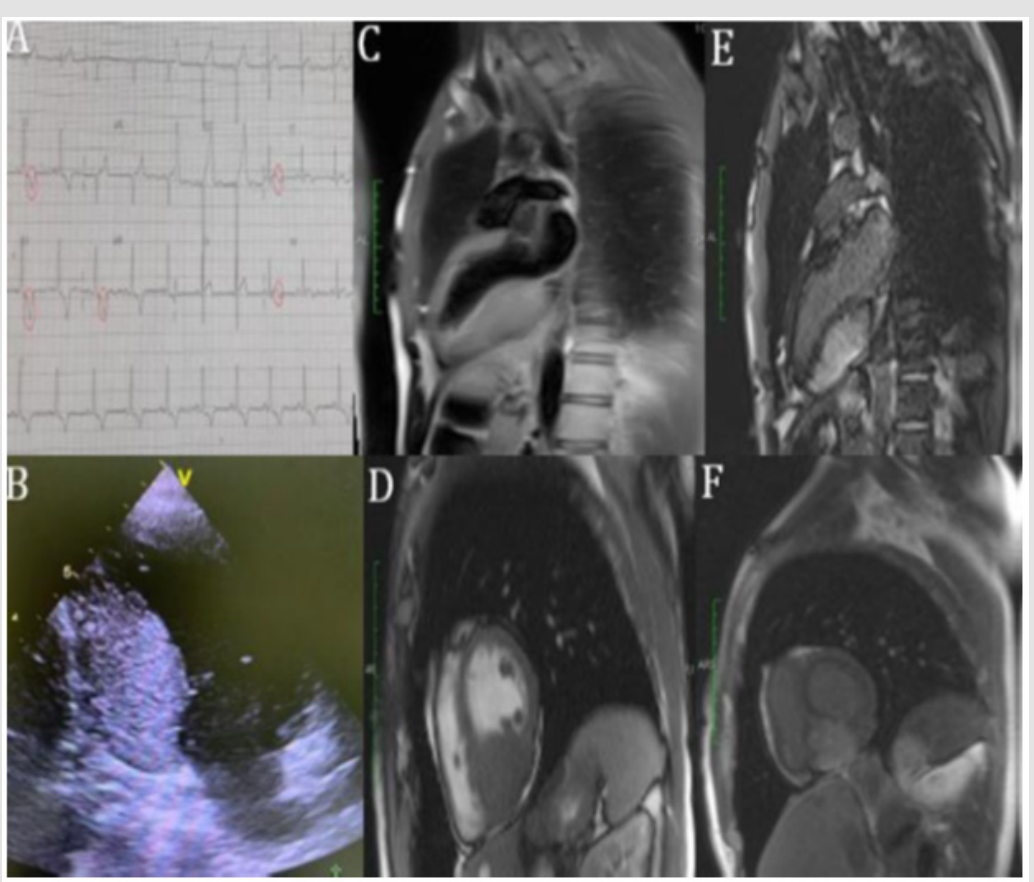

Figure 1:

a) EKG showing LV hypertrophy (Sokolow index at $39 \mathrm{~mm}$ ) and $\mathrm{T}$ waves inversion in infero-lateral leads

b) TTE 2-chamber view showing the myocardial mass in the inferior wall of the left ventricle

c) T1-weighted imaging 2-chamber view showing a hyperintense cardiac mass

d) T2-weighted imaging short-axis view showing a hypointense cardiac mass. Delayed enhanced imaging (2-chamber view at $2 \mathrm{~min}$ )

e) Short axis at $10 \mathrm{~min}$

f) Showing marked late hyperenhancement of the mass with gadolinium, which is a hallmark of cardiac fibroma.

\section{Conflict of Interest}

No conflict of interest with any institution/organization.

ISSN: 2574-1241

DOI: 10.26717/BJSTR.2021.40.006469

Oumaima ALAIKA. Biomed J Sci \& Tech Res

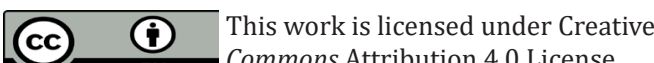

Submission Link: https://biomedres.us/submit-manuscript.php

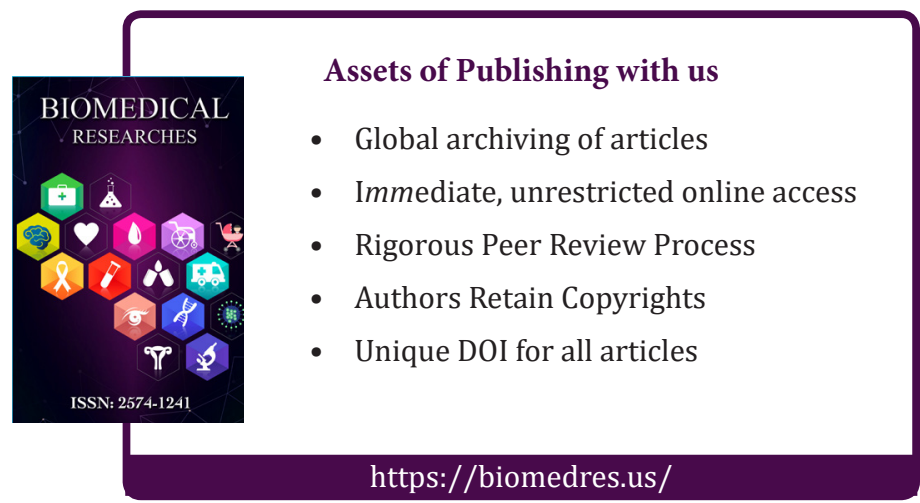

